\title{
Positive Association between Aspirin-Intolerant Asthma and Genetic Polymorphisms of FSIP1: a Case-Case Study
}

\author{
Jason Yongha Kim¹, Jeong Hyun Kim¹1, Tae Joon Park1, Joon Seol Bae1, Jin Sol Lee1, Charisse Flerida Pasaje1, Byung

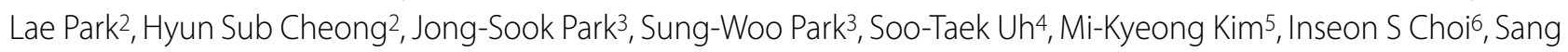 \\ Heon Cho ${ }^{7}$, Byoung Whui Choi ${ }^{8}$, Choon-Sik Park*3 and Hyoung Doo Shin*1,2
}

\begin{abstract}
Background: Aspirin-intolerant asthma (AIA), which is caused by non-steroidal anti-inflammatory drugs (NSAIDs) such as aspirin, causes lung inflammation and reversal bronchi reduction, leading to difficulty in breathing. Aspirin is known to affect various parts inside human body, ranging from lung to spermatogenesis. FSIP1, also known as HDS10, is a recently discovered gene that encodes fibrous sheath interacting protein 1, and is regulated by amyloid beta precursor protein (APP). Recently, it has been reported that a peptide derived from APP is cleaved by a disintegrin and metalloproteinase 33 (ADAM33), which is an asthma susceptibility gene. It has also been known that the FSIP1 gene is expressed in airway epithelium.
\end{abstract}

Objectives: Aim of this study is to find out whether FSIP1 polymorphisms affect the onset of AIA in Korean population, since it is known that AIA is genetically affected by various genes.

Methods: We conducted association study between 66 single nucleotide polymorphisms (SNPS) of the FSIP1 gene and AIA in total of 592 Korean subjects including 163 AIA and 429 aspirin-tolerant asthma (ATA) patients. Associations between polymorphisms of FSIP1 and AIA were analyzed with sex, smoking status, atopy, and body mass index (BMI) as covariates.

Results: Initially, 18 SNPs and 4 haplotypes showed associations with AIA. However, after correcting the data for multiple testing, only one SNP showed an association with AIA (corrected $P$-value $=0.03, O R=1.63,95 \% \mathrm{Cl}=1.23-2.16$ ), showing increased susceptibility to AIA compared with that of ATA cases. Our findings suggest that FSIP1 gene might be a susceptibility gene for aspirin intolerance in asthmatics.

Conclusion: Although our findings did not suggest that SNPS of FSIP1 had an effect on the reversibility of lung function abnormalities in AIA patients, they did show significant evidence of association between the variants in FSIP1 and AIA occurrence among asthmatics in a Korean population.

\section{Background}

Asthma is a disease that affects a large number of people globally, which is estimated to be about 300 million worldwide [1] and about 3 million asthma patients in South Korea. The disease is defined by the lung inflam-

*Correspondence: mdcspark@unitel.co.kr, hdshin@sogang.ac.kr

${ }^{3}$ Genome Research Center for Allergy and Respiratory Disease, Soonchunhyang University Bucheon Hospital, Bucheon, Republic of Korea 1 Department of Life Science, Sogang University, Seoul, Republic of Korea + Contributed equally

Full list of author information is available at the end of the article mation and difficulty of breathing when the suspect is under the influence of various factors that trigger the asthma reaction. Among these factors, non-steroidal anti-inflammatory drugs such as aspirin are known to cause aspirin-intolerant asthma. The AIA was first described in 1922 [2,3], and its most noticeable symptoms include aspirin sensitivity, bronchial asthma, and chronic rhinosinusitis with nasal polyposis [4-6]. When non-steroidal anti-inflammatory drugs such as aspirin are ingested, the drugs cause bronchoconstriction in the patients. Aspirin, also known as acetylsalicylic acid, is pri- 
marily used as pain and fever reliever, and as an antiinflammatory medication. One function of aspirin is decrease of prostaglandin production, with the most significant effect of decrease in the prostaglandin on the alleviation of inflammation and pain.

Recently, there have been several reports that found the relation between AIA and genetic polymorphisms, such as Adenosine A1 receptor (ADORA1) polymorphisms $1405 \mathrm{C}>\mathrm{T}$ and A102A [5]; several polymorphisms in prostaglandin receptors and thromboxane receptor [7]; Interleukin 10 (IL10) polymorphism -1082 A > G [8]; cysteinyl leukotriene receptor 1 (CYSLTR1) promoter polymorphism $-634 \mathrm{C}>\mathrm{T}[6]$; angiotensin I converting enzyme $(A C E)$ polymorphisms $-262 \mathrm{~A}>\mathrm{T}$ and $-115 \mathrm{~T}>\mathrm{C}$ [9]; and Fc Fragment of IgE (FCER1G) polymorphism 237A > G [10]. These results suggest that other genes or complex signal pathways might be related to the development of aspirin hypersensitivity in asthmatics.

Fibrous sheath interacting protein 1 gene (FSIP1), also known as $H S D 10$, is a recently discovered gene that was first described in 2003 [11]. With its primary function on protein binding, the FSIP1 gene is expressed in airway epithelium (GSE4498 and GDS2486, GEO database) [12]. It has been reported that FSIP1 is regulated by amyloid beta (A $\beta$ ) precursor protein (APP) [13]. APP is an integral membrane protein expressed in many tissues, and particularly, in the synapses of neurons. There has been a report that APP is cleaved by $\alpha$ disintegrin and metalloproteinase 33 (ADAM33), which is an asthma susceptibility gene $[14,15]$. Based on these findings, we hypothesized FSIP1 gene could have an effect on the mechanism of aspirin on the various levels, including onset of AIA, and conducted association analyses of FSIP1 gene polymorphisms between AIA and ATA patients. We also conducted association analyses between SNPs of FSIP1 and fall rate of $\mathrm{FEV}_{1}$ by aspirin provocation.

\section{Methods Study Subjects}

This study was conducted in compliance with the Global Initiative for Asthma (GINA) Global strategy for asthma management and prevention Study. A total of 592 subjects were recruited from the Asthma Genome Research Center comprising hospitals of Soonchunhyang Seoul and Bucheon Hospital, Chungnam, Chungbuk, and Seoul national university in Korea. All subjects provided informed consent, and the protocols were approved by the Institutional Review Board of each hospital. Each patient showed airway reversibility such as the inhalant bronchodilator-induced improvement with over $15 \%$ of forced expiratory volume in $1 \mathrm{~s}\left(\mathrm{FEV}_{1}\right)$ and/or the airway hyperresponsiveness to the provocative concentration of P20 methacholine [16]. Aspirin challenge was performed as previously described [17]. Subjects showing a fall rate of $\mathrm{FEV}_{1}$ less than $15 \%$ without skin manifestations were included in ATA group. The clinical profiles of subjects are listed in Table 1.

All patients had a history of dyspnea and wheezing during the previous 12 months, plus one of the following: 1) $>15 \%$ increase in FEV1 or $>12 \%$ increase plus $200 \mathrm{~mL}$ following inhalation of a short-acting bronchodilator, 2) $<10$ $\mathrm{mg} / \mathrm{mL}$ PC20 methacholine, and 3) $>20 \%$ increase in FEV1 following 2 weeks of treatment with inhaled steroids and long-acting bronchodilators. Twenty-four common inhalant allergens were used for a skin prick test [9]. Total IgE was measured by the CAP system (Pharmacia Diagnostics, Uppsala, Sweden). Atopy was defined as having a wheal reaction equal to or greater than histamine or $3 \mathrm{~mm}$ in diameter. The asthmatic patients had experienced no exacerbation of asthma and respiratory tract infection in the 6 weeks preceding oral aspirin challenge (OAC). OAC was performed with increasing doses of aspirin using methods slightly modified from those described previously $[9,18]$. Changes in $\mathrm{FEV}_{1}$ were followed for 5 hours after the last aspirin challenge dose. Aspirin-induced bronchospasms, as reflected by rate (\%) of $\mathrm{FEV}_{1}$ decline, were calculated as the pre-challenge $\mathrm{FEV}_{1}$ minus the post-challenge $\mathrm{FEV}_{1}$ divided by the prechallenge $\mathrm{FEV}_{1}$. OAC reactions were categorized into 2 groups as follows: $15 \%$ or greater decreases in $\mathrm{FEV}_{1}$ with naso-ocular or cutaneous reactions (aspirin intolerant asthma: AIA), and less than 15\% decreases in $\mathrm{FEV}_{1}$ without naso-ocular or cutaneous reactions (aspirin tolerant asthma: ATA).

\section{SNP selection and genotyping}

We selected candidate SNPs showing polymorphic in the National Center for Biotechnology Information (build 36 ), and then genotyped in 163 AIA and 429 ATA subjects. Genotyping was performed at a multiplex level of using the Illumina Golden Gate genotyping system [19] and data quality was assessed by duplicate DNAs $(\mathrm{n}=10)$. The genotype quality score for retaining data was set to 0.25 . SNPs that could not satisfy the following criteria were excluded: (i) a minimum call rate of $90 \%$; (ii) no duplicate error; (iii) Hardy-Weinberg equilibrium greater than $P>0.001$. A total of 66 SNPs from FSIP1 were successfully genotyped.

\section{Statistics}

We examined Lewontin's $\mathrm{D}^{\prime}\left(\left|D^{\prime}\right|\right)$ and the linkage disequilibrium (LD) coefficient $r^{2}$ between all pairs of biallelic loci. Linkage disequilibrium was inferred using the algorithm developed by the Broad Institute (using the program Haploview) [20]. Haplotypes were first estimated by using PHASE software [21], and then computed 
Table 1: Clinical profiles of AIA patients and ATA cases.

\begin{tabular}{llll}
\hline Clinical profile & Asthmatics (all subject) & AlA & ATA \\
\hline $\mathrm{N}$ & & & 429 \\
Age of first medical examination (mean (range)) & 462 & 163 & $47.30(15.40-77.88)$ \\
Height (cm) & $160.78 \pm 8.63$ & $161.72 \pm 8.69$ & $160.42 \pm 8.39$ \\
Weight (kg) & $62.81 \pm 10.84$ & $61.25 \pm 10.38$ & $63.40 \pm 10.97$ \\
Fall rate (\%) & $9.27 \pm 13.24$ & $24.63 \pm 16.11$ & $3.54 \pm 4.85$ \\
Blood eosinophil (\%) & $6.01 \pm 5.73$ & $5.96 \pm 5.21$ & $6.03 \pm 5.92$ \\
FVC \%, predicted & $88.54 \pm 14.08$ & $90.35 \pm 14.04$ & $87.85 \pm 14.05$ \\
FEV $\%$, predicted & $90.54 \pm 16.97$ & $87.58 \pm 16.94$ & $91.66 \pm 16.87$ \\
PC20, methacholine (mg/ml) & $6.43 \pm 8.67$ & $5.02 \pm 7.83$ & $6.91 \pm 8.90$ \\
Total lgE (IU/ml)* & $156(62,394)$ & $164(78,357)$ & $154(53,416)$ \\
Sex (male/female) & $206 / 386$ & $59 / 104$ & $147 / 282$ \\
Current Smoker (\%) & 27.70 & 21.47 & 30.07 \\
Positive rate of skin test (\%) & 56.42 & 52.76 & 57.81 \\
\hline
\end{tabular}

Fall rate refers to the decline of $\mathrm{FEV}_{1} \%$ by aspirin provocation.

*Total IgE value is shown as median (25\% interquartile interval, $75 \%$ interquartile interval).

AIA, aspirin-intolerant asthma; ATA, aspirin-tolerant asthma; FVC, forced vital capacity; FEV , forced expiratory volume in 1 second.

by logistic analyses using the Statistical Analysis System (SAS). Subjects harboring missing genotypes were omitted in the analysis of individual single-nucleotide polymorphisms and haplotypes. The genotyping success rate was $>99 \%$, so it is unlikely that omitting a small number of individuals introduced any bias in the analysis. The genotype and haplotype association with AIA were analyzed using logistic models with age (continuous value), gender $($ male $=0$, female $=1$ ), smoking status (nonsmoker $=0$, ex-smoker $=1$, smoker $=2)$, atopy $($ absence $=$ 0 , presence $=1)$, and BMI as covariates. Significant associations are shown in bold face $(P<0.05)$. The common alleles were used as the referent genotype to the heterozygote and homozygote of the minor allele in referent analysis. The association analyses of differences in the fall rates in $\mathrm{FEV}_{1}$ following aspirin challenge with the genotypes and haplotypes were examined by regression analysis using SAS. The data were managed and analyzed using SAS. The effective numbers of independent marker loci in each genes were calculated to correct for multiple testing using the software SNPSpD [22], which is based on the spectral decomposition $(\mathrm{SpD})$ of matrices of pair-wise LD between SNPs [22].

\section{Results}

\section{Subject Characteristics}

A total of 592 asthma patients were recruited for this study, and there were 163 AIA patients and 429 ATA cases (Table 1). First of all, the fall rate by aspirin provocation in AIA patients showed significantly higher fall rate $(24.63 \%)$ than ATA cases $(3.54 \%)(P<0.0001$, Table 1). Among the total subjects, $27.70 \%$ were current smokers, with more smokers within ATA patients $(30.07 \%)$ than AIA patients (21.47\%). Also, the positive skin test rate of AIA was smaller than that of ATA patients (52.76 and 57.81 , respectively).

\section{SNP Analyses}

Figure 1 shows the physical map of FSIP 1 , which contains 66 SNPs of the FSIP1 gene along with positions at exons and introns. Most of the variants were located in intronic regions (Additional File 1). In case of SNPs in coding region, two nonsynonymous SNPs, rs10152640 and rs16969386, were located in exon11 region, and they also caused amino acid change, with the former causing cysteine to arginine amino acid change at position 402, while the latter caused glycine to alanine amino acid change at position 528 .

In logistic analysis for associations between SNPs of FSIP1 and AIA in a Korean population with adjustment for age, sex, smoking status, atopy and BMI, there was 18 SNPs showing initial significant associations and one SNP showing significant association after correction ( rs7179742, $P=0.0007$, Pcor. $=0.03, \mathrm{OR}=1.63,95 \% \mathrm{CI}=$ 1.23-2.16). Detailed analyses of $r s 7179742$, along with other SNPs in the same haplotype block (FSIP1_BL1), are shown in Table 2. Although rs7179742 was the only SNP with significant relation after correction for multiple testing, SNPs in FSIP1_BL1 had considerably significant $P$ values before correction for multiple testing. Further- 


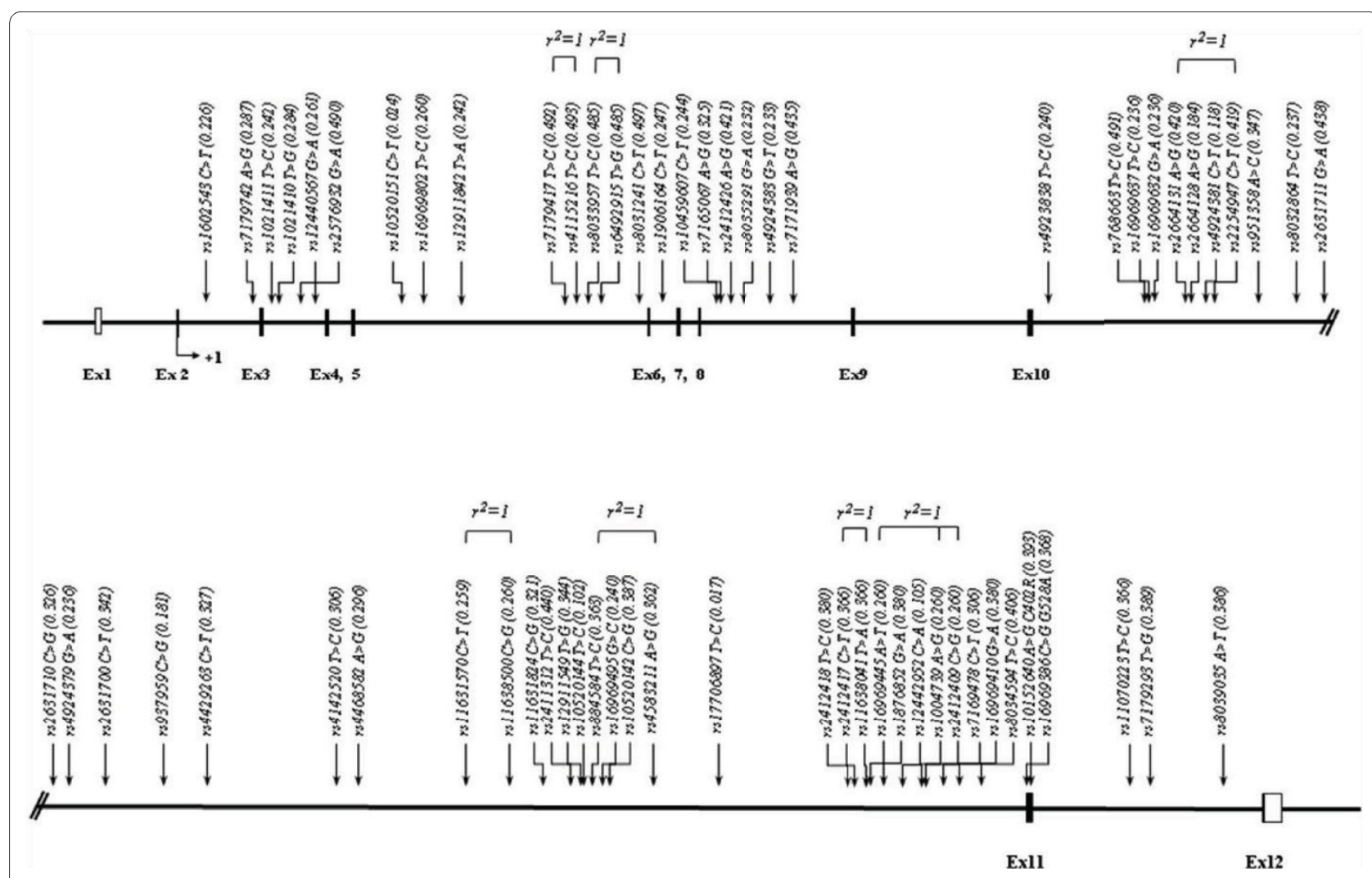

Figure 1 A physical map of FSIP1 on chromosome 15q14. Exons, introns, UTR, and SNPs are shown. Coding exons are marked by shaded blocks; UTRs by white blocks. SNPs with complete LD are represented by $r^{2}=1$.

more, SNPs in FSIP1_BL1 including rs7179742 were observed to have an effect on the increased fall rate of $\mathrm{FEV}_{1}$ by aspirin provocation (Table 3 ).

Logarithms for $P$-values of all SNPs were calculated for the better representation of the values (Figure 2). Simultaneously, negative $\log$ of 0.05 and 0.0001 , where latter value equals to 0.05 after correction for multiple testing (multiple testing correction number $=49.39$ ), show the lines for significant association. In particular, SNPs with its value exceeding lower line (negative log of 0.05 ) would have initial association with AIA, and if it exceeds upper line (negative log of 0.0001), it would still have significant association after correction for multiple testing. As shown in Figure 2, there were 18 SNPs out of 66 that showed initial significant association with AIA. 12 SNPs out of the 18 showed association with the susceptibility to the risk of AIA, furthermore, rs7179742 had significantly higher MAF for AIA than that of ATA, showing increased susceptibility of AIA (MAF $=0.358$ and 0.262 , respectively). On the other hand, six SNPs out of the 18 showed lower minor allele frequencies in AIA patients compared to those of ATA cases.

\section{Haplotypes Analyses}

Haplotypes were calculated using PHASE software, and there were 3 haplotype blocks identified (Figure 3). Interestingly, pair-wise comparisons showed tight LD with three LD blocks among 66 SNPs of the FSIP1 gene. From each haplotype blocks, a total of 13 haplotypes with frequencies higher than 0.05 are listed (Figure 3A). Among them, 4 haplotypes showed initial association with AIA, as detailed analyses of the haplotypes are listed in Table 4. Three haplotypes, FSIP1_BL1_ht4 $(P=0.03)$, FSIP1_BL2_ht4 $(P=0.02), F S I P 1 \_B L 3 \_h t 3(P=0.04)$ and FSIP1_BL3_ht4 $(P=0.01)$, were frequent in AIA patients, whereas FSIP1_BL3_ht3 revealed a lower frequency in AIA compared to that of ATA cases, respectively. However, their signals disappeared after the correction for multiple testing.

\section{Discussion}

Most of the SNPs were located in intronic region, but two SNPs, rs10152640 and rs16969386, were located in exon region. They also caused amino acid change, as rs 10152640 caused cysteine to arginine amino acid change at position 402 and $r s 16969386$ caused glycine to alanine amino acid change at position 528 . Nonsynonymous amino acid changes have significant effect on the 
Table 2: Logistic and statistical analyses of FSIP1 SNPs in haplotype block 1.

\begin{tabular}{|c|c|c|c|c|c|c|c|c|c|}
\hline \multirow[t]{2}{*}{ rs\# } & \multirow[t]{2}{*}{ Position } & \multicolumn{3}{|c|}{ MAF } & \multirow[t]{2}{*}{ Heterozygosity } & \multirow[t]{2}{*}{ HWE } & \multirow[t]{2}{*}{ OR(95\%Cl) } & \multirow[t]{2}{*}{$P$} & \multirow[t]{2}{*}{ Pcor } \\
\hline & & AIA & ATA & Total & & & & & \\
\hline rs1602543 & Intron2 & 0.199 & 0.235 & 0.226 & 0.350 & 0.997 & $0.81(0.59-1.11)$ & 0.19 & 1.00 \\
\hline rs7179742 & Intron2 & 0.358 & 0.262 & 0.287 & 0.409 & 0.765 & $1.63(1.23-2.16)$ & 0.0007 & 0.03 \\
\hline rs1021411 & Intron3 & 0.292 & 0.227 & 0.242 & 0.367 & 0.885 & $1.47(1.09-1.98)$ & 0.01 & 0.55 \\
\hline rs1021410 & Intron3 & 0.352 & 0.262 & 0.284 & 0.407 & 0.751 & $1.60(1.20-2.13)$ & 0.001 & 0.06 \\
\hline rs 12440567 & Intron3 & 0.325 & 0.240 & 0.261 & 0.386 & 0.788 & $1.58(1.18-2.10)$ & 0.002 & 0.09 \\
\hline rs2576932 & Intron3 & 0.443 & 0.508 & 0.490 & 0.500 & 0.786 & $0.75(0.58-0.98)$ & 0.03 & 1.00 \\
\hline rs10520151 & Intron5 & 0.027 & 0.023 & 0.024 & 0.047 & 0.274 & $1.17(0.53-2.59)$ & 0.70 & 1.00 \\
\hline rs16969802 & Intron5 & 0.322 & 0.239 & 0.260 & 0.384 & 0.705 & $1.56(1.17-2.08)$ & 0.002 & 0.11 \\
\hline rs12911842 & Intron5 & 0.211 & 0.260 & 0.242 & 0.367 & 0.467 & $0.73(0.54-0.99)$ & 0.04 & 1.00 \\
\hline rs7179417 & Intron5 & 0.446 & 0.509 & 0.492 & 0.500 & 0.815 & $0.76(0.59-0.98)$ & 0.04 & 1.00 \\
\hline rs4115216 & Intron5 & 0.446 & 0.510 & 0.493 & 0.500 & 0.877 & $0.76(0.58-0.98)$ & 0.03 & 1.00 \\
\hline rs8033957 & Intron5 & 0.527 & 0.468 & 0.485 & 0.500 & 0.511 & $1.28(1.00-1.66)$ & 0.05 & 1.00 \\
\hline rs6492915 & Intron5 & 0.527 & 0.468 & 0.485 & 0.500 & 0.511 & $1.28(1.00-1.66)$ & 0.05 & 1.00 \\
\hline rs8031241 & Intron5 & 0.452 & 0.513 & 0.497 & 0.500 & 0.905 & $0.76(0.59-0.99)$ & 0.04 & 1.00 \\
\hline rs1906164 & Intron6 & 0.232 & 0.249 & 0.247 & 0.372 & 0.852 & $0.91(0.67-1.23)$ & 0.53 & 1.00 \\
\hline
\end{tabular}

MAF, minor allele frequency; AIA, aspirin-intolerant asthma; ATA, aspirin-tolerant asthma; HWE, Hardy-Weinberg Equilibrium;

$\mathrm{OR}$, odds ratio; $\mathrm{Cl}$, confidence interval; $P$ cor., corrected $P$-value.

expression and function of the protein [23,24]. In particular, the hydrophobicity change from cysteine to arginine (2.5 and -4.5 of hydrophobicity, respectively) on the rs 10152640 could induce a critical conformational or functional change of the protein. However, when the association between two nonsynonymous SNPs of FSIP1 and the fall rate of $\mathrm{FEV}_{1}$ by aspirin provocation was analyzed, no significant association was found (data not shown), indicating that these nonsynonymous variants could not have a direct effect on the activities of FSIP1 protein.

From the association analyses of FSIP1 gene with AIA, we initially found 18 polymorphisms that showed association. In addition, significant associations of several SNPs in FSIP1_BL1 and FSIP1_BL2 with the fall rate of $\mathrm{FEV}_{1}$ by aspirin provocation were found (data for FSIP1_BL2 not shown). However, after multiple testing correction, only $r s 7179742\left(P=0.0007, P^{c o r} .=0.03, \mathrm{OR}=1.63,95 \% \mathrm{CI}=\right.$ 1.23-2.16) showed increased susceptibility of AIA. The possible susceptibility of $r s 7179742$ to AIA was reinforced by the significant association of this variant with the increased fall rate of $\mathrm{FEV}_{1}$ by aspirin provocation $(P=$ 0.01 in co-dominant model, Table 3 ). Although this SNP is located in the intronic region of the gene, intronic region can still affect overall transcription in different ways. It was reported that introns can affect transcription efficiency [25], and another study demonstrated that variations in intronic region can lead to splicing abnormalities, which in turn may lead to human diseases [26]. It was also reported recently that a SNP located in intronic region showed an association with asthma [27]. On the other hand, in additional analysis of LD near FSIP1 in Asian populations (Chinese and Japanese) from the International HapMap Project http://hapmap.ncbi.nlm. nih.gov/, the FSIP1 gene is in LD with the thrombospondin-1 (THBS1 or TSP-1) gene (Additional File 2). The THBS1 gene has been implicated in the network underlying the pulmonary response to oxidative stress in asthma [28]. More interestingly, aspirin, as an inhibitor of THBS1, has recently shown to lead to reduction in THBS1 levels [29]. This suggests that FSIP1 might have an effect on aspirin hypersensitivity in asthma, with relation to the nearby potential gene of THBS1.

The FSIP1 gene has been discovered very recently. FSIP1 is regulated by APP, an integral member protein that is found in many tissues. APP, in turn, is cleaved by an asthma susceptible gene called ADAM33 [30]. $A D A M 33$ polymorphisms have been associated with asthma risk in various populations, including Korea [31], Thai, Han Chinese and Japanese [32-34], who are closely related with Korean population, especially Han Chinese and Japanese. The ADAM33 polymorphisms have also 
Table 3: Association analysis between SNPs of FSIP1 gene and the fall of FEV 1 by aspirin provocation.

\begin{tabular}{|c|c|c|c|c|c|c|c|}
\hline \multirow[t]{2}{*}{ rs\# } & \multicolumn{2}{|r|}{$\mathrm{C} / \mathrm{C}$} & \multicolumn{2}{|r|}{$\mathbf{C} / \mathbf{R}$} & \multicolumn{2}{|r|}{$R / R$} & \multirow[t]{2}{*}{$P^{*}$} \\
\hline & $\mathbf{n}$ & Fall rate & $\mathbf{n}$ & Fall rate & $\mathbf{n}$ & Fall rate & \\
\hline rs1602543 & 356 & $9.74 \pm 13.12$ & 205 & $8.25 \pm 13.03$ & 31 & $9.88 \pm 15.55$ & 0.43 \\
\hline rs7179742 & 300 & $8.29 \pm 12.05$ & 241 & $9.49 \pm 14.15$ & 51 & $13.54 \pm 14.55$ & 0.01 \\
\hline rs1021411 & 335 & $8.84 \pm 12.89$ & 223 & $9.58 \pm 13.87$ & 34 & $10.88 \pm 12.14$ & 0.26 \\
\hline rs1021410 & 299 & $8.30 \pm 12.03$ & 245 & $9.56 \pm 14.13$ & 48 & $13.38 \pm 14.86$ & 0.01 \\
\hline rs 12440567 & 322 & $8.36 \pm 12.33$ & 227 & $9.81 \pm 14.15$ & 43 & $12.76 \pm 14.11$ & 0.02 \\
\hline rs 2576932 & 157 & $11.33 \pm 15.8$ & 290 & $8.34 \pm 11.80$ & 144 & $8.76 \pm 12.69$ & 0.06 \\
\hline rs 10520151 & 564 & $9.15 \pm 13.02$ & 27 & $0.71 \pm 17.32$ & 1 & 13.8 & 0.50 \\
\hline rs16969802 & 324 & $8.38 \pm 12.32$ & 225 & $9.80 \pm 14.18$ & 43 & $12.68 \pm 14.14$ & 0.02 \\
\hline rs12911842 & 341 & $9.57 \pm 13.93$ & 210 & $9.30 \pm 12.54$ & 41 & $6.09 \pm 9.94$ & 0.14 \\
\hline rs7179417 & 156 & $11.40 \pm 15.8$ & 291 & $8.25 \pm 11.78$ & 145 & $8.87 \pm 12.64$ & 0.06 \\
\hline rs4115216 & 155 & $11.46 \pm 15.8$ & 292 & $8.23 \pm 11.77$ & 145 & $8.87 \pm 12.64$ & 0.06 \\
\hline rs8033957 & 162 & $9.08 \pm 13.21$ & 284 & $8.22 \pm 11.59$ & 145 & $11.41 \pm 15.8$ & 0.10 \\
\hline rs6492915 & 162 & $9.08 \pm 13.21$ & 284 & $8.22 \pm 11.59$ & 145 & $11.41 \pm 15.8$ & 0.10 \\
\hline rs8031241 & 153 & $11.52 \pm 15.9$ & 291 & $8.20 \pm 11.76$ & 147 & $8.91 \pm 12.62$ & 0.06 \\
\hline rs1906164 & 339 & $9.25 \pm 12.60$ & 216 & $9.21 \pm 13.94$ & 37 & $9.24 \pm 14.74$ & 0.98 \\
\hline
\end{tabular}

${ }^{*} P$-values of regression analysis represent the co-dominant model controlling sex, smoking status, and atopy as covariates.

$\mathrm{C} / \mathrm{C}, \mathrm{C} / \mathrm{R}$ and $\mathrm{R} / \mathrm{R}$ indicate the homozygote of common allele, and the heterozygote and homozygote of rare allele, respectively.

Fall rate values are mean \pm standard deviation.

been related with asthma risk of smoking population $[35,36]$. These results suggest that the FSIP1 gene could have a correlation with APP and/or ADAM33 in development of asthma. In addition, the fact that aspirin affects wide range of human body, from lung to blood clotting to spermatogenesis, has to be considered. Naturally, the mechanism and pathways of aspirin is intricate and complicated.

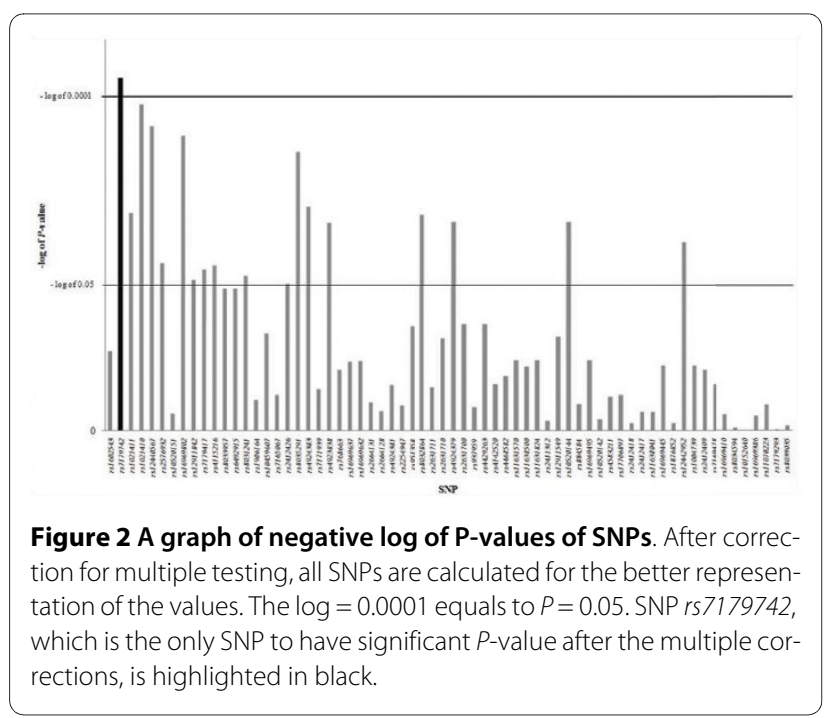

One of limitation of our study is the small number of AIA patient, which might result in decreasing the statistical power of this study. However, considering the rareness of AIA condition, our results could provide supporting information, with further needs of replication in large number of subjects. Taken together, even though current knowledge of FSIP1 gene implicates that it only affects a small part out of aspirin pathways, our findings suggest a new relation between FSIP1 and aspirin hypersensitivity that explains the association found in this study.

\section{Conclusions}

In summary, we found 18 SNPs and 4 haplotypes of FSIP1 showing associations with AIA initially, and after multiple testing correction, one SNP, rs7179742 showed significant association with AIA. Although the relation between the FSIP1 gene and AIA is not yet clearly understood, our findings suggest that FSIP1-related regulations of APP and ADAM33 may play a role for the development of aspirin hypersensitivity in asthmatics, along with the fact that FSIP1 is expressed in airway epithelium. Future researches should concentrate on this part to discover more about the role of FSIP 1 gene and also the relation between the gene and various diseases including AIA. 
Table 4: Logistic and statistical analyses of FSIP1 haplotypes.

\begin{tabular}{|c|c|c|c|c|c|c|c|c|}
\hline \multirow[t]{2}{*}{ Haplotypes } & \multicolumn{3}{|c|}{ MAF } & \multirow[t]{2}{*}{ Heterozygosity } & \multirow[t]{2}{*}{ HWE } & \multirow[t]{2}{*}{ OR (95\%CI) } & \multirow[t]{2}{*}{$P$} & \multirow[t]{2}{*}{ Pcor. } \\
\hline & AIA & ATA & Total & & & & & \\
\hline FSIP1__BL1_ht1 & 0.235 & 0.256 & 0.254 & 0.379 & 0.770 & $0.91(0.67-1.23)$ & 0.52 & 1.00 \\
\hline FSIP1-_BL1_ht2 & 0.202 & 0.241 & 0.227 & 0.351 & 0.683 & $0.76(0.55-1.03)$ & 0.08 & 1.00 \\
\hline$F S I P 1$ 1_BL1_ht3 & 0.187 & 0.214 & 0.208 & 0.330 & 0.498 & $0.85(0.62-1.16)$ & 0.30 & 1.00 \\
\hline FSIP1__BL1_ht4 & 0.244 & 0.190 & 0.202 & 0.322 & 0.546 & $1.42(1.04-1.94)$ & 0.03 & 1.00 \\
\hline FSIP1-_BL2_ht1 & 0.262 & 0.302 & 0.295 & 0.416 & 0.614 & $0.82(0.62-1.09)$ & 0.18 & 1.00 \\
\hline$F S I P 1-B B L 2 \_h t 2$ & 0.199 & 0.226 & 0.214 & 0.336 & 0.207 & $0.82(0.60-1.11)$ & 0.20 & 1.00 \\
\hline FSIP1-_BL2_ht3 & 0.130 & 0.148 & 0.146 & 0.250 & 0.400 & $0.88(0.61-1.27)$ & 0.49 & 1.00 \\
\hline FSIP1-_BL2_ht4 & 0.151 & 0.098 & 0.111 & 0.197 & 0.908 & $1.61(1.10-2.37)$ & 0.02 & 0.76 \\
\hline FSIP1-_BL2_ht5 & 0.123 & 0.104 & 0.109 & 0.195 & 0.839 & $1.34(0.89-2.01)$ & 0.17 & 1.00 \\
\hline FSIP1-_BL3_ht1 & 0.238 & 0.291 & 0.283 & 0.406 & 0.011 & $0.78(0.59-1.04)$ & 0.09 & 1.00 \\
\hline FSIP1-_BL3_ht2 & 0.298 & 0.269 & 0.278 & 0.401 & 0.600 & $1.21(0.91-1.60)$ & 0.19 & 1.00 \\
\hline FSIP1-_BL3_ht3 & 0.157 & 0.202 & 0.187 & 0.304 & 0.575 & $0.70(0.50-0.98)$ & 0.04 & 1.00 \\
\hline FSIP1-_BL3_ht4 & 0.117 & 0.072 & 0.085 & 0.155 & 0.200 & $1.76(1.13-2.74)$ & 0.01 & 0.66 \\
\hline
\end{tabular}

MAF, minor allele frequency; AIA, aspirin intolerant asthma; ATA, aspirin tolerant asthma; HWE, Hardy-Weinberg equilibrium number; OR, odd ratio; $\mathrm{Cl}$, confidence interval; $P$ cor., corrected $P$-value.

(A)

Block 1 Block 2
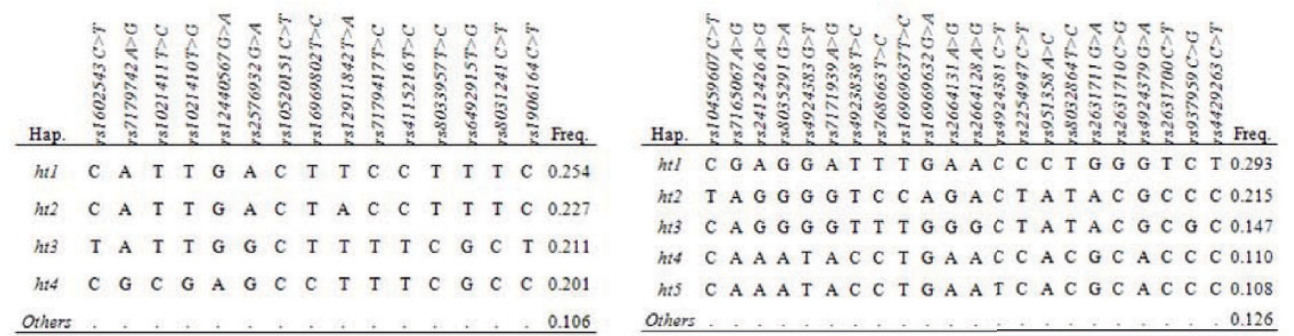

(B)



Figure 3 Haplotypes and LDs of FSIP1 gene. (A) Haplotypes of FSIP1 in the Korean population. They are divided into 3 haplotype blocks. Only those with frequencies over 0.05 are shown. (B) LD coefficients graphical plot (|D'|) among SNPs based on the genotypes of whole study subjects in this study $(n=592)$ 


\section{Additional material}

Additional file 1 Supplementary Table 1- SNPs of FSIP1 and their $P$ value. The table contains all the SNPS of FSIP1 examined in our study and their P-value. This includes SNPs from haplotype block 2 and 3.

Additional file $\mathbf{2}$ Supplementary Figure $\mathbf{1}$ - LD plot nearby FSIP1. The LD near FSIP1 in Asian populations (Chinese and Japanese) is analyzed from the International HapMap Project http://hapmap.ncbi.nIm.nih.gov/. LD coefficient (D') among SNPS of THBS1, FSIP1, and GPR176 in Asian populations. The FSIP1 is in LD with THBS1 with a LD block.

\section{Abbreviations}

FSIP1: Fibrous sheath-interacting protein 1; AIA: Aspirin-intolerant asthma; ATA: Aspirin-tolerant asthma; APP: Amyloid beta (A 3 ) precursor protein; ADAM33: a disintegrin and metalloproteinase 33; SNP: Single nucleotide polymorphism; BMI: Body mass index; FEV 1 : Forced expiratory volume in 1 second; IgE: Immuglobulin E; OAC: Oral aspirin challenge; PAF: Platelet activating factor; ht: Haplotype; FVC: Forced Vital Capacity; $P$ : $P$ value, and Pcor: Corrected $P$ value; LD: Linkage Disequilibrium; THBS1: Thrombospondin-1

\section{Competing interests}

The authors declare that they have no competing interests.

\section{Authors' contributions}

JYK and JHK developed tables/figures, and drafted the manuscript. TJP, JSL, and CFP participated in preparation and quality control of samples. JSB, BLP, and HSC performed the statistical analysis. JSP, SWP, STU, MKK, ISC, SHC, and BWC helped to recruit subjects. CSP and HDS managed all of this study and helped to draft the manuscript. All authors read and approved the final manuscript.

\section{Acknowledgements}

This work was supported by a grant from the Korea Health 21 R\&D Project (A010249); a grant number M1-0302-00-0073 from Korea Science and Engineering Foundation (KOSEF) funded by the Korea government (MEST) (No. 2009-0080157); an Intramural Research Grant of the Korea National Institute of Health (grant number 4800-4845-300-260-00); an Intramural Research Grant from Sogang University (grant number 200810021.01); and a Priority Research Centers Program through the National Research Foundation of Korea (NRF) funded by the Ministry of Education, Science and Technology (2009-0093822). The DNA samples were generously provided by the Soonchunhyang University, Bucheon Hospital Biobank, a member of the National Biobank of Korea, supported by the Ministry of Health, Welfare and Family Affairs, Republic of Korea.

\section{Author Details}

1Department of Life Science, Sogang University, Seoul, Republic of Korea, 2Department of Genetic Epidemiology, SNP Genetics, Inc., Seoul, Republic of Korea, ${ }^{3}$ Genome Research Center for Allergy and Respiratory Disease, Soonchunhyang University Bucheon Hospital, Bucheon, Republic of Korea, ${ }^{4}$ Division of Allergy and Respiratory Medicine, Soonchunhyang University Seoul Hospital, Seoul, Republic of Korea, ${ }^{5}$ Division of Internal Medicine, Chungbuk National University, College of Medicine, Cheongju, Republic of Korea, ${ }^{6}$ Department of Allergy, Chonnam National University Medical School and Research Institute of Medical Sciences, Gwangju, Republic of Korea, ${ }^{7}$ Department of Internal Medicine and Institute of Allergy and Clinical Immunology, Seoul National University College of Medicine, Seoul, Republic of Korea and ${ }^{8}$ Division of Pulmonology and Allergy, Department of Internal Medicine, Chung-Ang University Yongsan Hospital, Seoul, Republic of Korea

Received: 4 March 2010 Accepted: 1 June 2010

Published: 1 June 2010

\section{References}

1. Fanta CH: Asthma. NEngl J Med 2009, 360:1002-1014.

2. Widal F, Abrami P, Lermoyez J: Anaphylaxie et idiosyncrasie. 1992 [Anaphylaxis and idiosyncrasy. 1992]. Allergy Proc 1993, 14:373-376. discussion 371-372

3. Babu KS, Salvi SS: Aspirin and asthma. Chest 2000, 118:1470-1476.
4. Kim SH, Hur GY, Choi JH, Park HS: Pharmacogenetics of aspirin-intolerant asthma. Pharmacogenomics 2008, 9:85-91.

5. Kim SH, Kim YK, Park HW, Kim SH, Kim SH, Ye YM, Min KU, Park HS: Adenosine deaminase and adenosine receptor polymorphisms in aspirin-intolerant asthma. Respir Med 2009, 103:356-363.

6. Kim SH, Ye YM, Hur GY, Lee SK, Sampson AP, Lee HY, Park HS: CysLTR1 promoter polymorphism and requirement for leukotriene receptor antagonist in aspirin-intolerant asthma patients. Pharmacogenomics 2007, 8:1143-1150.

7. Kim SH, Kim YK, Park HW, Jee YK, Kim SH, Bahn JW, Chang YS, Kim SH, Ye YM, Shin ES, et al: Association between polymorphisms in prostanoid receptor genes and aspirin-intolerant asthma. Pharmacogenet Genomics 2007, 17:295-304.

8. Kim SH, Yang EM, Lee HN, Cho BY, Ye YM, Park HS: Combined effect of IL10 and TGF-beta 1 promoter polymorphisms as a risk factor for aspirinintolerant asthma and rhinosinusitis. Allergy 2009, 64:1221-1225.

9. Kim TH, Chang HS, Park SM, Nam BY, Park JS, Rhim T, Park HS, Kim MK, Choi IS, Cho SH, et al: Association of angiotensin I-converting enzyme gene polymorphisms with aspirin intolerance in asthmatics. Clin Exp Allergy 2008, 38:1727-1737.

10. Palikhe NS, Kim SH, Cho BY, Ye YM, Hur GY, Park HS: Association of three sets of high-affinity IgE receptor (FcepsilonR1) polymorphisms with aspirin-intolerant asthma. Respir Med 2008, 102:1132-1139.

11. Brown PR, Miki K, Harper DB, Eddy EM: A-kinase anchoring protein 4 binding proteins in the fibrous sheath of the sperm flagellum. Biol Reprod 2003, 68:2241-2248.

12. Harvey BG, Heguy A, Leopold PL, Carolan BJ, Ferris B, Crystal RG Modification of gene expression of the small airway epithelium in response to cigarette smoking. J Mol Med 2007, 85:39-53.

13. Wen GY, Yang SY, Kaczmarski W, He XY, Pappas KS: Presence of hydroxysteroid dehydrogenase type 10 in amyloid plaques (APs) of Hsiao's APP-Sw transgenic mouse brains, but absence in APs of Alzheimer's disease brains. Brain Res 2002, 954:115-122.

14. Sakagami T, Jinnai N, Nakajima T, Sekigawa T, Hasegawa T, Suzuki E, Inoue I, Gejyo F: ADAM33 polymorphisms are associated with aspirinintolerant asthma in the Japanese population. J Hum Genet 2007, 52:66-72.

15. Zou J, Zhu F, Liu J, Wang W, Zhang R, Garlisi CG, Liu YH, Wang S, Shah H, Wan Y, et al:: Catalytic activity of human ADAM33. J Biol Chem 2004, 279:9818-9830.

16. Crapo RO, Casaburi R, Coates AL, Enright PL, Hankinson JL, Irvin CG, Maclntyre NR, McKay RT, Wanger JS, Anderson SD, et al:: Guidelines for methacholine and exercise challenge testing-1999. This official statement of the American Thoracic Society was adopted by the ATS Board of Directors, July 1999. Am J Respir Crit Care Med 2000, 161:309-329.

17. Lee SH, Rhim T, Choi YS, Min JW, Kim SH, Cho SY, Paik YK, Park CS: Complement $\mathrm{C} 3 \mathrm{a}$ and $\mathrm{C} 4 \mathrm{a}$ increased in plasma of patients with aspirininduced asthma. Am J Respir Crit Care Med 2006, 173:370-378.

18. Cormican LJ, Farooque S, Altmann DR, Lee TH: Improvements in an oral aspirin challenge protocol for the diagnosis of aspirin hypersensitivity. Clin Exp Allergy 2005, 35:717-722.

19. Oliphant A, Barker DL, Stuelpnagel JR, Chee MS: BeadArray technology: enabling an accurate, cost-effective approach to high-throughput genotyping. Biotechniques 2002:56-58. 60-51

20. Barrett JC, Fry B, Maller J, Daly MJ: Haploview: analysis and visualization of LD and haplotype maps. Bioinformatics 2005, 21:263-265.

21. Stephens M, Smith NJ, Donnelly P: A new statistical method for haplotype reconstruction from population data. Am J Hum Genet 2001, 68:978-989

22. Single Nucleotide Polymorphism Spectral Decomposition (SNPSpD) [http://genepi.aimr.edu.au/general/daleN/SNPSpD/]

23. Shastry BS: SNPs: impact on gene function and phenotype. Methods Mol Biol 2009, 578:3-22.

24. Barenboim M, Jamison DC, Vaisman II: Statistical geometry approach to the study of functional effects of human nonsynonymous SNPs. Hum Mutat 2005, 26:471-476.

25. Brinster RL, Allen JM, Behringer RR, Gelinas RE, Palmiter RD: Introns increase transcriptional efficiency in transgenic mice. Proc Natl Acad Sci USA 1988, 85:836-840

26. Pagani F, Baralle FE: Genomic variants in exons and introns: identifying the splicing spoilers. Nat Rev Genet 2004, 5:389-396. 
27. Jung JS, Park BL, Cheong HS, Bae JS, Kim JH, Chang HS, Rhim T, Park JS, Jang AS, Lee YM, et al:: Association of IL-17RB gene polymorphism with asthma. Chest 2009, 135:1173-1180.

28. Freishtat RJ, Benton AS, Watson AM, Wang Z, Rose MC, Hoffman EP: Delineation of a gene network underlying the pulmonary response to oxidative stress in asthma. J Investig Med 2009, 57:756-764.

29. Fouladkou F, Lu C, Jiang C, Zhou L, She Y, Walls JR, Kawabe H, Brose N, Henkelman RM, Huang A, et al: The ubiquitin ligase Nedd4-1 is required for heart development and is a suppressor of thrombospondin-1. J Biol Chem 285:6770-6780.

30. Weiss ST, Raby BA, Rogers A: Asthma genetics and genomics 2009. Curr Opin Genet Dev 2009, 19:279-282.

31. Lee JH, Park HS, Park SW, Jang AS, Uh ST, Rhim T, Park CS, Hong SJ, Holgate ST, Holloway JW, et al:: ADAM33 polymorphism: association with bronchial hyper-responsiveness in Korean asthmatics. Clin Exp Allergy 2004, 34:860-865.

32. Thongngarm T, Jameekornrak A, Limwongse C, Sangasapaviliya A, Jirapongsananuruk O, Assawamakin A, Chaiyaratana N, Luangwedchakarn V, Thongnoppakhun W: Association between ADAM33 polymorphisms and asthma in a Thai population. Asian Pac J Allergy Immunol 2008, 26:205-211.

33. Noguchi E, Ohtsuki Y, Tokunaga K, Yamaoka-Sageshima M, Ichikawa K, Aoki T, Shibasaki M, Arinami T: ADAM33 polymorphisms are associated with asthma susceptibility in a Japanese population. Clin Exp Allergy 2006, 36:602-608.

34. Su D, Zhang X, Sui H, Lu F, Jin L, Zhang J: Association of ADAM33 gene polymorphisms with adult allergic asthma and rhinitis in a Chinese Han population. BMC Med Genet 2008, 9:82.

35. Sadeghnejad A, Ohar JA, Zheng SL, Sterling DA, Hawkins GA, Meyers DA, Bleecker ER: Adam33 polymorphisms are associated with COPD and lung function in long-term tobacco smokers. Respir Res 2009, 10:21.

36. Reijmerink NE, Kerkhof M, Koppelman GH, Gerritsen J, de Jongste JC, Smit HA, Brunekreef B, Postma DS: Smoke exposure interacts with ADAM33 polymorphisms in the development of lung function and hyperresponsiveness. Allergy 2009, 64:898-904.

\section{Pre-publication history}

The pre-publication history for this paper can be accessed here: http://www.biomedcentral.com/1471-2466/10/34/prepub

doi: 10.1186/1471-2466-10-34

Cite this article as: Kim et al., Positive Association between Aspirin-Intolerant Asthma and Genetic Polymorphisms of FSIP1: a Case-Case Study BMC Pulmonary Medicine 2010, 10:34

Submit your next manuscript to BioMed Central and take full advantage of:

- Convenient online submission

- Thorough peer review

- No space constraints or color figure charges

- Immediate publication on acceptance

- Inclusion in PubMed, CAS, Scopus and Google Scholar

- Research which is freely available for redistribution

Submit your manuscript at www.biomedcentral.com/submit
Ciomed Central 